\title{
The Long Arms of Anencephaly: A Refutation
}

\author{
Mason Barr Jr.* \\ Teratology Unit, Department of Pediatrics, Pathology, and Obstetrics, University of Michigan, Ann Arbor, Michigan
}

Received 20 February 2009; Revised 19 March 2009; Accepted 25 March 2009

A paper published in 1925 reported that human fetuses with anencephaly have arms that are longer than normal. This finding was accepted as true through the early 1990s. An analysis of body dimensions done in 1996 and enlarged and updated here shows that the arms of human fetuses with anencephaly are appropriate for gestational age and normal in proportion to their leg lengths. A subtle difference in measurement technique was found to explain the discordant findings. Birth Defects Research (Part A) 85:710-714, 2009. (c) 2009 Wiley-Liss, Inc.

\section{INTRODUCTION}

In 1925 Juan Nañagas published an elegant study of external dimensions of 57 anencephalic human fetuses (Nañagas, 1925). The one remarkable finding of this study was that the arms of anencephalics were considerably longer (by $21.8 \mathrm{~mm}$ or $11.9 \%$ on average) than expected. This finding has been cited a number of times in the subsequent literature (Lemire et al., 1972, 1975, 1978; Goodman and Gorlin, 1983; Gorlin et al., 1990). In 1996, in a study of body dimensions and visceral weights of 54 anencephalic fetuses, I found that their arms and legs showed no significant deviation from those of agematched normal fetuses. This was reported at a Smith Workshop (Barr, 1977) but not presented in a formal paper. At the urging of two different citers of Nañagas's work, I have repeated parts of the 1996 study with a larger sample and have confirmed my earlier finding that the arms of anencephalics are no longer than they should be for either gestational age or leg length. Further evaluation disclosed the reason for the discrepancy from Nañagas's findings.

\section{MATERIALS AND METHODS}

From a sample of 131 anencephalic fetuses, 16 were excluded because of incomplete measurement, advanced deterioration, trisomy 18 , or combinations of these three. The sample size used was 115 (35 meroacrania and 80 holoacrania, 31 of the latter with rachischisis below midneck). All fetuses were fresh and measured by the same prosector using the same technique.

Measurements, in millimeters, of both anencephalics and controls were done as follows: (1) Arm length: from the tip of the acromion to the tip of the third digit, with the arm in full extension and parallel to the long axis of the body. (2) Leg length: from the perineal surface to the sole of the foot, with the leg fully extended in the long axis of the body and the foot at 90 degrees to the axis of the leg; this is identical to crown-heel length (CHL) minus crown-rump length (CRL).

Control standards (expected mean and SD) were derived from 1155 morphologically normal, autopsied fetuses. These fetuses were from a larger sample that had been screened for outliers ( $z$-scores on preliminary curve fitting $>+3.5$ or $<-3.5)$. Any fetus with two or more outlying $z$-scores was excluded from the analysis (Barr et al., 1994). For the linear measures considered here, curve fitting for means and $95 \%$ confidence limits was by best fit using power equations. Since Nañagas relied primarily on arm length versus leg length to reach his conclusions, that comparison was used in this study. Here z-score distributions were determined for both normal and anencephalic fetuses using the same power equation derived from normal fetuses.

Age data for most of the normal fetuses were validated by early ultrasonography. In the absence of early ultrasonic validation, the given dates were accepted if the growth parameters were consistent with those fetuses whose age had been confirmed by early ultrasonography.

The normal measurements used by Nañagas were obtained from the work of Scammon and Calkins (1929, hereafter referred to as $\mathrm{S} \& \mathrm{C}$ ). For linear versus linear measurements, both straight-line regressions (as used in the Minnesota studies of $\mathrm{S} \& \mathrm{C}$ ) and more highly correlated Michigan power equations were used, enabling comparison of the Minnesota and Michigan data with reasonable confidence. For linear versus age measurements, second-degree polynomial equations had a better

In honor of Thomas H. Shepard, mentor, colleague, and friend

*Correspondence to: Mason Barr Jr., MD, Teratology Unit, Pediatric Genetics, D5240 MPB/5718, University of Michigan Medical Center, Ann Arbor, MI 48109-5718. E-mail: barr@med.umich.edu

Published online 13 May 2009 in Wiley InterScience (www.interscience. wiley.com).

DOI: $10.1002 /$ bdra.20591 

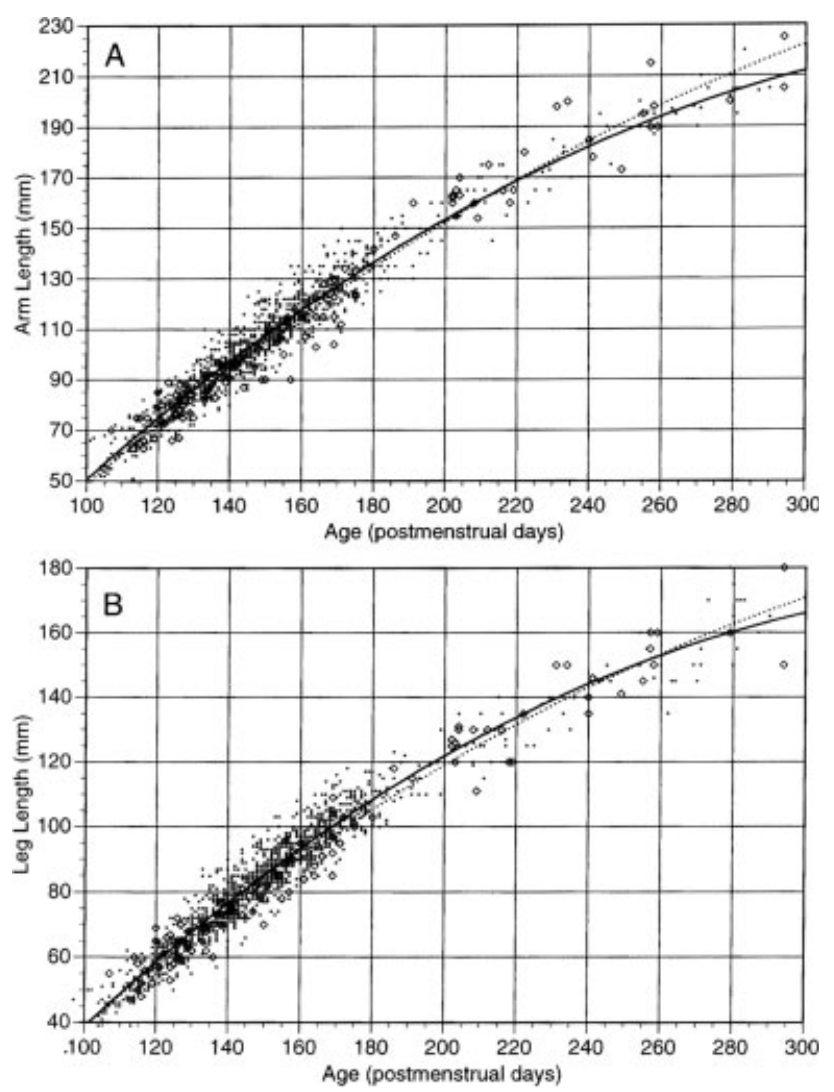

Figure 1. Lengths of arm (A) and leg (B) versus gestational age, fitted with second-degree polynomial curves. Normal fetuses: dots and solid line. Anencephalic fetuses: open diamonds and dotted line.

fit to the scatterplots than did the linear equations used by S\&C. When comparisons between the Michigan and Minnesota data were attempted, linear equations were used on both data sets to demonstrate the degree of correspondence between the two.

\section{RESULTS}

Scatterplots of arm length and leg length versus postmenstrual age showed no meaningful difference between anencephalic and normal fetuses (Fig. 1). When the data were fitted for means, the normal and anencephalic fetuses were virtually indistinguishable. Plotting arm length versus leg length, with incorporation of the mean and $95 \%$ confidence limits, showed the anencephalic fetuses well within the confidence limits, except six that were high and three that were low (Fig. 2). Again the means were virtually identical. The $z$-score distributions demonstrated the similarity of the two populations (Fig. 3). To validate that measurements from the Minnesota studies of S\&C were concordant with the measurement obtained in the Michigan studies, the empiric formulae published by S\&C were graphed on the scatterplots of the Michigan data from normal fetuses (Fig. 4). Leg length of the Minnesota sample was adjusted to the method used for the Michigan sample by using the S\&C empiric formulae for CHL minus CRL. The resulting

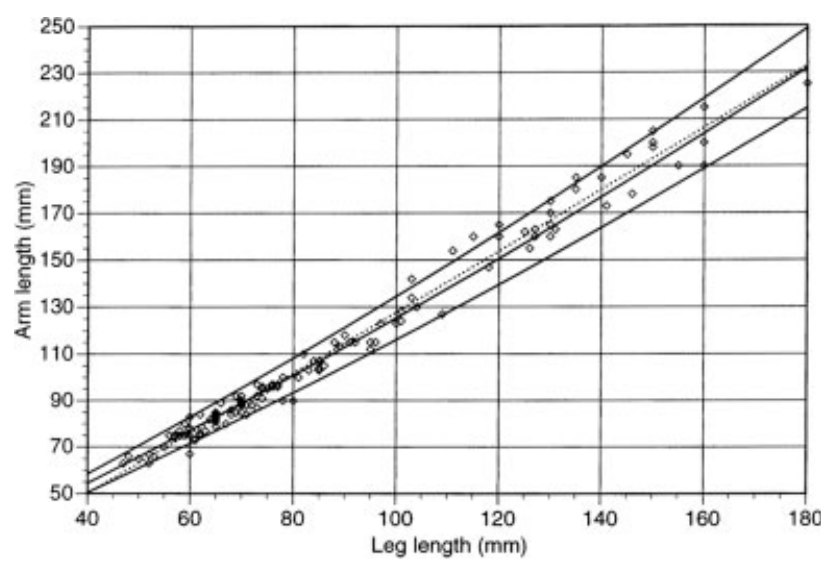

Figure 2. Arm length versus leg length. Solid lines: mean and 95\% confidence limits of 1155 normal fetuses. Open diamonds: 115 anencephalic fetuses. Dotted line: mean of anencephalics

plots of arm length versus CHL showed great similarity when curve fittings were by linear equations and not substantively different from more highly correlated power curves (Fig. 4).

\section{DISCUSSION}

I decided to explore these morphometrics because, on encountering the assertion that the arms of anencephalic fetuses were unduly long, my initial impression was that this was likely an illusion: an illusion due to the shortening of their vertebral columns by kyphotic and lordotic curvatures. The requisite information for this exploration was at hand, since limb measurements had been routinely obtained on many both normal and abnormal fetuses.

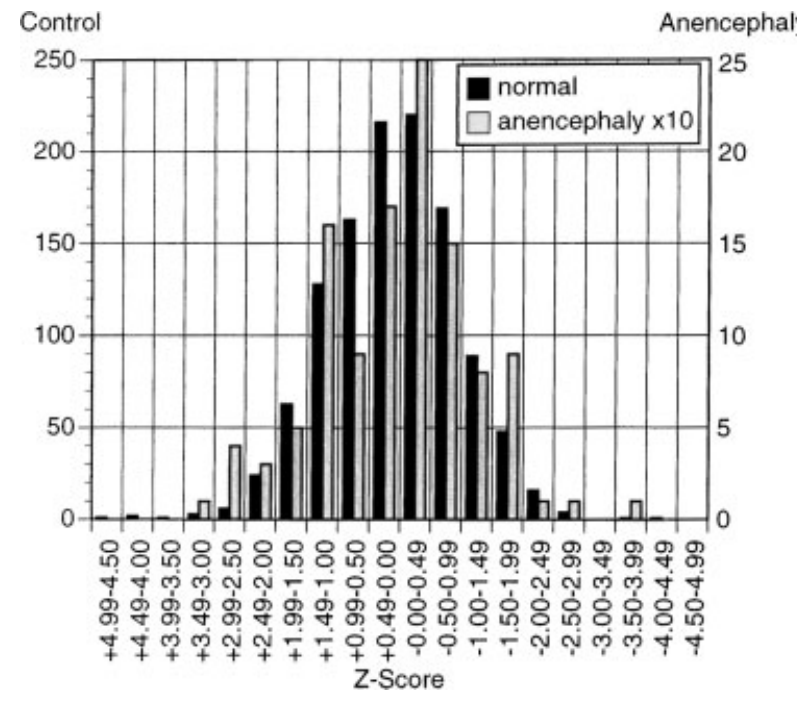

Figure 3. Arm versus leg $z$-score distribution. Calculated by the formula derived from normal fetuses: Expected arm $=$ $\left(\operatorname{leg}^{\left(0.9745-\left(3.423 \times 10^{-4} \times \mathrm{leg}\right)+\left(1.836 \times 10^{-6} \times \mathrm{leg}^{2}\right)\right)}\right) \times 1.5127 ;$ fetuses: Expected arm $=$ $\left(\operatorname{leg}^{\left(0.9745-\left(3.423 \times 10^{-4} \times \operatorname{leg}\right)+\left(1.836 \times 10^{-6} \times \operatorname{leg}^{2}\right)\right)}\right) \times \quad 5.687 \times 10^{-2} ; z$-score: (observed arm - expected arm) / SD. 

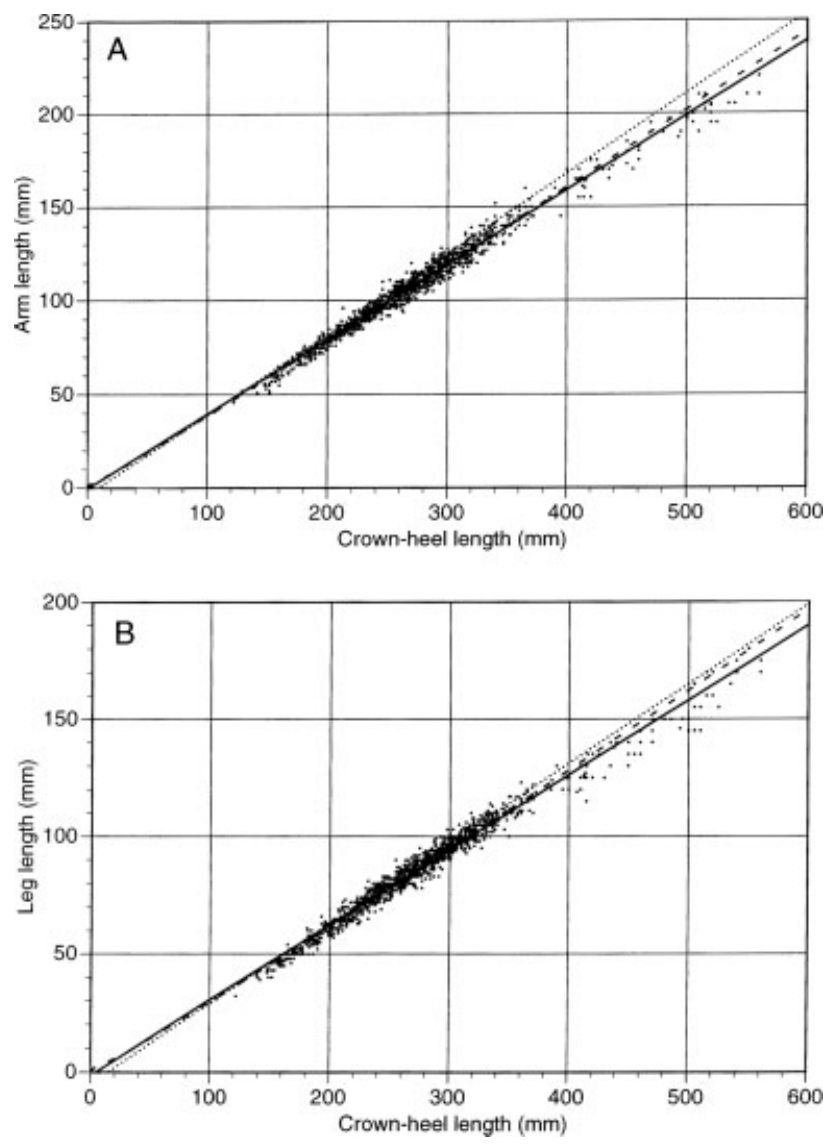

Figure 4. (A) Arm length versus CHL. (B) Leg length versus CHL. In both panels the dots are the observed data from normal Michigan fetuses. The solid lines are the means plotted as linear equations, the dashed lines are the means plotted as power equations, and the dotted lines are from the empiric linear equations published by S\&C.

Nañagas's study was done in the laboratory of R. E. Scammon at the University of Minnesota contemporaneously with the monumental study by S\&C of the external dimensions of the human fetus (Nañagas, 1925; Scannon and Calkins, 1929). This study was the source of normative data used by Nañagas and thus was integral to the anencephaly study.

When the length of the upper extremity in the anencephalic fetus was plotted against that of the lower extremity Nañagas found that the resulting curve lay at an average of $21.8 \mathrm{~mm}$ above the curve for normal fetuses, and all the anencephalics' arms were longer than normal. The anencephalic arm was $11.9 \%$ longer on average than normal, and the disproportion diminished distally: the upper arm $24 \%$, forearm $16 \%$, and hand $2 \%$ longer, respectively. In his Figure 9 (arm length vs. leg length), he showed clearly separated but parallel lines for growth of the arms of anencephalic and normal fetuses.

I do not know why Nañagas decided to study the morphometrics of anencephalic fetuses, but once he had done so and found that their arms were longer than expected, he quite naturally sought to explain why or how this came about. Speculation about the cause (the why) or the mechanism (the how) of an observation (the what) is of use only to frame hypotheses for further testing; it is not to be used to validate the observation.

In his attempt to understand why the arms of anencephalics were longer than normal, Nañagas discussed various possibilities. He suggested that in anencephaly there is an early disturbance in growth that then ceases, allowing the body to resume a normal course of proportional growth. The arm would have temporarily become the more active growing part, and at the same time the accelerated growth of the upper extremities would dominate that of the more caudal segments and inhibit overgrowth on their part, so only the arms would be overgrown. Where does this line of thinking come from?

It derives from a hypothesis proposed by Child that in turn seems to derive from a hypothesis, proposed by Wilhelm Roux, involving a struggle among body parts competing for limited nutrition (Roux, 1881; Child, 1915). Nañagas wrote, "If we accept Child's concept that the body of embryo shows a definite axial gradation in which the apical gradient or head is more vigorous and dominates the development of the succeeding ones, we may conceive that in the present instance the retardation of development of the apical gradient has weakened this dominance and that the succeeding gradient, as represented in this case by the upper extremities, has become temporarily the more active growing part."

He specifically suggested "the arrest of the development of the head in its critical period of growth, as indicated by the marked defects of the brain and its supporting structures, has removed the inhibition which the rapidly growing cephalic region normally exerts upon the growth of the superior limb buds." Nañagas adduced further support for this idea from the work of Stockard (1921).

Stockard discussed discontinuous modes of development due to lowered temperature or restricted oxygen supply to the developing fish embryo. He described partial or complete arrest of development and the effect on the proportions of embryo parts in subsequent development. Stockard's interpretation of this work is summarized as follows: "When one organ or one component has a higher rate than another, it develops at this rate for a limited time and tends to inhibit development on the part of other organs. This is readily demonstrated by the inhibiting effect of the growing shoot over all the potential buds of a plant. When the growing tip is pinched away, the inhibited buds immediately express their capacity to grow. There is much evidence to indicate that a similar interaction exists among the developing parts of an animal embryo" (Stockard, 1921, p. 260). However, he cited no direct evidence for this last statement in his paper.

However, I think that Nañagas misapplied Stockard's ideas by suggesting that the defect of the brain and supporting structures found in anencephaly would temporarily remove the inhibition that the rapidly growing cephalic region supposedly exerts upon the growth of the superior limb buds. He proposed that with the removal of the inhibition exerted by the head, the arms "would have the opportunity to increase to abnormal dimensions during their period of critical growth."

"Cephalic inhibition" of more caudal growth in animals now seems to be a concept with little if any scientific support. The concept of a period of "critical growth" in the present context is also of doubtful validity. Naña- 
gas posited an early growth disturbance, 'before the lower extremity is fully differentiated." The long-term effect of transiently arrested development would be more relevant to hypodevelopment, as in restriction of cell number, than to hyperdevelopment. I think overgrowth is more likely to be a late event (fetal as opposed to embryonic), and the genesis of anencephaly is clearly an embryonic event.

Nañagas concluded, "In the teratological condition known as anencephaly there is an excessive development of the superior extremity. This hyperdevelopment is most prominent proximally and decreases distally in accordance with the general law of cephalocaudal growth." S\&C comment on a "law of developmental direction," which they found preferable to the "law of cephalocaudal development" used by others. Their reasoning was that their terminology covered not only cephalocaudal but mediodistal gradients as well. Be that as it may, I do not think either concept reaches the stature of "law." A less all-embracing term would at least admit the obviously small arms of $T$. rex and the greatly elongated "fingers" of bats. Also, as S\&C note, even in humans the distally placed legs end up outgrowing the proximally placed arms in length.

This hypothesizing harkens back to the era following the introduction of evolutionary theory when there was a grand search for overarching laws of development. The ideas discussed were not considered exceptional at the time. That the proposal of "laws" sometimes went too far is evident now, but at the time these proposals seemed to make sense (provided one did not find reallife variation too unsettling). We can now recognize that the "laws" of cephalocaudal development or developmental direction have too many exceptions to be considered laws. These days, by parsing the details of developmental schedules, we find deeper and deeper layers of complexity that were unimagined in the late nineteenth and early twentieth centuries.

Aside from current rejection of such conjectures, there is a more compelling reason to reject the application of such suppositions to explain the long arms of anencephalic fetuses. That reason is that the arms of anencephalics are not unduly long. If my claim is that the arms of anencephalics are not longer than normal, it is incumbent on me to try to discover why Nañagas found otherwise. His study appeared to be carefully done and clearly described. That his proposals for the why of his findings are incorrect is irrelevant.

There are some differences in the measurement methods used in the Minnesota and Michigan studies. The Minnesota fetuses were all formalin fixed, while the Michigan fetuses were unfixed. However, $S \& C$ in a pilot study found minimal shrinkage of extremity measurements after prolonged fixation, on the order of $0.3 \%$, not $12 \%$.

For leg measurements, the methods of S\&C and Nañagas are concordant. S\&C sum the leg segments as follows: from the greater trochanter to the center of the knee joint, from there to the center of the ankle joint, and from there to the sole of the foot. Nañagas sums the leg segments as follows: from the greater trochanter to the lateral condyle of the tibia, from there to the most prominent part of the lateral maleolus, and thence to the sole of the foot. The lateral condyle of the tibia is just below the center of knee joint and the lateral maleolus is just above the center of the ankle joint, so these two misplace- ments result in shortened foreleg measurements, but the total leg lengths agree with those of S\&C.

It must be noted that the legs of Minnesota fetuses were measured from the greater trochanter, while the legs of the Michigan fetuses were measured from the perineum. I find the latter technique more reproducible than the S\&C method, especially in the young fetus whose trochanter is minimally developed. The leg lengths reported by S\&C are approximately $26 \%$ greater on average than those of age-matched Michigan fetuses. However, if the calculation CHL minus CRL equals leg length is applied to the $S \& C$ data, there are negligible differences from my observations of leg lengths (Fig. 4). This indicates that there was actually no substantive difference in leg lengths between the Minnesota and Michigan fetuses.

S\&C's graphs and tables record extremity measurements for CHL and gestational age (in lunar months). Nañagas did not have age data for his specimens, and the CHL in anencephaly is obviously not to be considered normal. He estimated CHL from his measured leg lengths: "When the crown-heel length of the body is calculated from this [leg length] with the empiric formula [leg length $=0.43 \mathrm{CHL}-7.0 \mathrm{~mm}$ ], the resulting values range from 279 to $500 \mathrm{~mm}$, which may be regarded as within reasonable limits for normal material." (The method of estimating arm length from CHL was arm length $=0.43 \mathrm{CHL}-4.0 \mathrm{~mm}$ ).

In his Figure 9, Nañagas showed what appear to be parallel ascending lines denoting the arm length versus leg length for normal fetuses and for anencephalic fetuses. Since Nañagas and I did not measure leg lengths in the same way, I cannot construct a graph of arm versus leg that is directly comparable to his Figure 9. However, if the difference between anencephalic and normal fetuses were a constant average of $11.9 \%$, these lines would clearly diverge with continued growth. If the difference between anencephalic and normal arms were a constant $21.8 \mathrm{~mm}$, the lines would be parallel, as shown by Nañagas and imply a decreasing percentage difference with continued growth.

The upper extremity length is commonly defined as the distance in a straight line from the lateral tip of the acromial process to the end of the middle finger. The arms of the Michigan fetuses were measured from the acromion to the tip of the third finger as a single, straight-line measurement. The Minnesota fetuses were fixed specimens with flexed limbs. The method used by S\&C was "the length of the superior extremity is the sum of the distances from the acromial process to the angle of the elbow, from the angle of the elbow to the base of the palm of the hand, and from the base of the palm of the hand to the tip of the middle finger." When the $S \& C$ data for arm length versus $\mathrm{CHL}$ are contrasted with the comparable Michigan data there is close agreement (Fig. 4).

None of this so far provides an adequate explanation for the difference between Nañagas's findings and mine.

However, a close reading of the methods of arm measurement published by S\&C and by Nañagas does provide the answer. For $S \& C$ the focal point at the elbow was "the angle of the elbow joint." As shown in their Figure 1, the angle of the elbow is the antecubital crease, which is coincident with the center of elbow joint of the extended arm. If they measured from the antecubital crease with the arm flexed, their forearm measurement 
would have been too short. I think they actually did measure to the center of the elbow joint either by extending the arm or by making the adjustment to the joint center, because we get very similar readings of total arm length. But Nañagas, claiming identical measuring technique to $S \& C$, gave the following: "1. UEL, length of the upper extremity; the sum of the separate lengths of arm, forearm, and hand. 2. AL, arm length; from the tip of the acromium [sic] to the tip of the olecranon process. 3. FML, forearm length; from the tip of the olecranon process to the middle of the wrist joint. 4. HL, hand length; from the middle of the wrist joint to the tip of the middle finger."

The tip of the olecranon process is not coincident with the center of the elbow joint. So, rather than measuring the true length of the arm, Nañagas's summation of upper arm + forearm + hand has overstated arm length, predominantly of the proximal segment, but also of the distal limb to a lesser degree. By measuring arm length by both of these methods (assuming S\&C meant the middle of the elbow joint) and by my linear method in a sample of eight normal fetuses, I found that Nañagas's method produced lengths that were $12.25 \%$ greater than the S\&C and Michigan methods, which agreed with each other. This excess is so close to Nañagas's findings that the arms of anencephalics were on average $11.9 \%$ longer than normal that I believe the mystery is solved.

\section{REFERENCES}

Barr M. 1997. Is it true what they say about anencephalics? A morphometric analysis. Proc Greenwood Genet Ct 16:201-202.

Barr M, Blackburn WR, Cooley NR. 1994. Human fetal somatic and visceral morphometrics. Teratology 49:487-496.

Child CM. 1915. Senescence and rejuvenescence. Chicago: University of Chicago Press.

Goodman RM, Gorlin RJ. 1983. The malformed infant and child. New York: Oxford University Press (illustration on p. 4 labeled with "long arms").

Gorlin RJ, Cohen Jr. MM, Levin LS. 1990. Syndromes of the head and neck. 3rd ed. New York: Oxford University Press (p. 566).

Lemire RJ, Beckwith JB, Shepard TH. 1972. Iniencephaly and anencephaly with spinal retroflexion. A comparative study of eight human specimens. Teratology 6:27-36.

Lemire RJ, Beckwith JB, Warkany J. 1978. Anencephaly. New York: Raven Press (p. 63).

Lemire RJ, Loeser JD, Leech RW, Alvord Jr. EC. 1975. Normal and abnormal development of the human nervous system. Hagerstown, MD: Harper \& Row (p. 307, Table 18-4).

Nañagas JC. 1925. A comparison of the growth of the body dimensions of anencephalic human fetuses with normal growth as determined by graphical analysis and empirical formulae. Am J Anat 35:455-494.

Roux W. 1881. Der Kampf der Teile im Organismus [The Battle of Parts in the Organism]. Leipzig.

Scammon RE, Calkins LA. 1929. The development and growth of the external dimensions of the human body in the fetal period. Minneapolis: University of Minnesota Press.

Stockard CR. 1921. Developmental rate and structural expression: an experimental study of twins, 'double monsters', and single deformities and the interaction among embryonic organs during their origin and development. Am J Anat 28:115-277. 